\title{
ON MIGRANTS AND COVID-19 PANDEMIC - AN ANALYSIS
}

\section{Romana Emilia CRAMARENCO, PhD}

Faculty of European Studies, Babeş-Bolyai University Cluj-Napoca, Romania

romana.cramarenco@ubbcluj.ro

\begin{abstract}
In the present context of COVID 19 pandemic, the interlinkages between migration and health are once again on the international agenda. The relationship between migration and health is multifaceted and varies across migrant groups or individuals within groups. Sometimes, migration is driven by health issues, and in other cases the migration journey may worsen the health condition of the migrants and refugees, namely those migrating out of necessity. In Europe, the public health policies insufficiently address the health problems of the migrants, especially for displaced persons and irregular migrants. The impact of lockdowns and various socioeconomic restrictions on the most vulnerable labour force are being investigated nowadays, and the SDG principle "no one is left behind" is seriously challenged. The article aims to reveal several traits of the present health crisis and its impact on migrants and refugees, the vulnerabilities exacerbated by the crisis, and to identify potential measures to be taken by host countries in order to reduce the negative impact.
\end{abstract}

Keywords: migration, migration-health nexus, COVID 19 pandemic, migrants' vulnerabilities.

\section{Preliminary}

Since the beginning of 2020, the world has been witnessing one of the most dramatic health crisis, namely the COVID-19 pandemic. Up to October 2020, according to World Health Organisation (WHO), more than 43 million confirmed cases and more than 1 million deaths were registered. Since October this year, the so called second wave is reported in several countries in Europe.

OECD launched a territorial impact analysis of COVID-19 crisis showing that more than half of the world's population has experienced a lockdown with strong containment measures. This 
analysis is so relevant from the perspective of crisis response and management. The report reveals 3 dimensions of the COVID impact on regions (OECD, 2020:2)

1. Health/social impact: some regions, particularly the more vulnerable ones, such as deprived urban areas, have seen higher caseloads and mortality rates than others. Vulnerable populations, including migrants and refugees too, have been more affected.

2. Economic impact: regional economic exposure to the crisis is varying based on an area's exposure to global value chains and specialisation in specific sectors like tourism or hospitality, at least in the initial stages

3. Fiscal impact: the crisis is resulting in increased expenditure and reduced revenue for subnational governments, and while its impact on subnational finance is not uniform, it is expected to be long-lasting.

According to IOM, 259 million international migrants and more than 150 million workers were registered in 2017. A genuine and sustainable integration of the migrants in the host country depends greatly on their access to labour market, housing facilities and healthcare services. Still, in most European countries the issues of availability, accessibility, acceptability and quality of health services for migrants are far from being properly addressed. Moreover, "while the 2030 Agenda calls for social protection for all and aims for universal health coverage, national legislation often excludes international migrants in an irregular situation from social protection and affords other categories of migrants, such as temporary migrants, only limited rights" (UN, 2018:77).

The migration-health nexus has been analysed by a variety of researchers and among the most relevant perspectives, we mention the following - the human rights and social equity perspective, focusing on migration as a social determinant of the health of migrants (Davies et al, 2006), the social justice perspective (Clapham et al, 2009 in Arloth, 2010), the social exclusion (Wilkinson\&Marmot, 2003), the climate change-migration-health nexus (McMichael, 2020) or the gender perspective (Petrozziello, 2003, Ujano-Bataga, 2013).

We do consider the map proposed by Migration Data Portal a very useful one, for a better understanding of the interlinkages between migration phenomenon and health status of the migrants: 
Graph 1 Migration - health nexus

\section{MIGRATION AND THE SOCIAL DETERMINANTS OF HEALTH}

\section{Conditions surrounding migration often fuel health inequities and may expose migrants to increased health risks and negative health outcomes.}

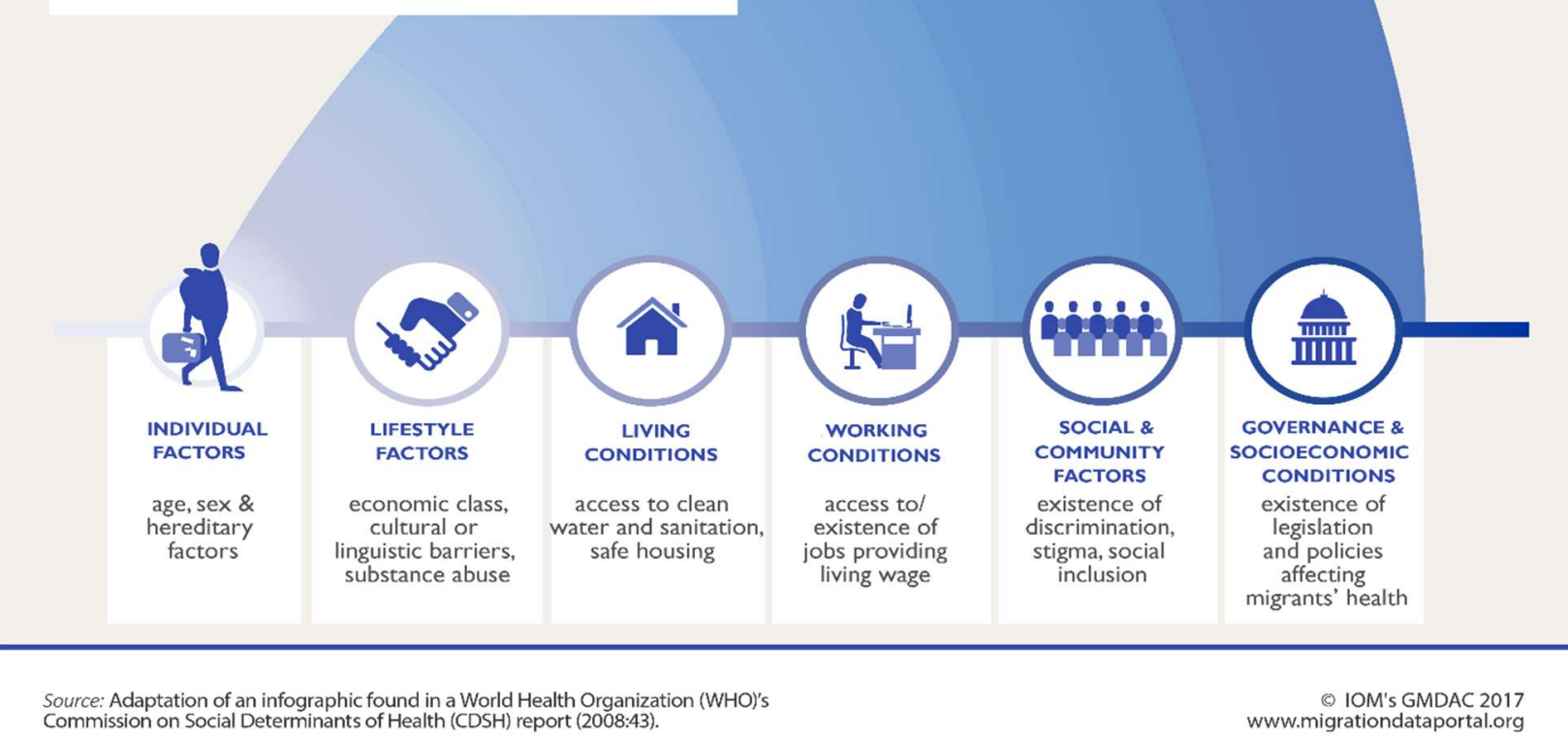

Source: https://migrationdataportal.org/themes/migration-and-health

Starting from the individual factors, the way the host environment is preserving, enhancing or damages the health status of migrants is crucial. From the push-pull theory perspective, we find that some migrants leave their country of origin in search for a better life, for a functioning society that protects or upgrades their socio-economic status or for access to qualitative healthcare systems. Others are forced to return to their home countries due to health problems that impacts their capacity to perform jobs on the host labour market. And others try to escape an exploitative working environment in the host country that affects their physical and emotional state. For those migrating out of necessity ${ }^{l}$ (refugees, asylum seekers), due to the hardships of their journey, their

\footnotetext{
${ }^{1}$ In the case of circular/back and forth forms of migration, it has been noticed a spread of health conditions or behaviours between destination and origin areas, affecting the health status of migrants. In the case of refugees and asylum seekers, the very limited access to healthcare services negatively impacts their health status.
} 
health, and sometimes their lives are put at high risks. Therefore, access to healthcare services provided by the transition and host countries is a must.

Graph 2 Migration phases and health related factors

Factors influencing the health and well-being of migrants and their families along the phases of migration

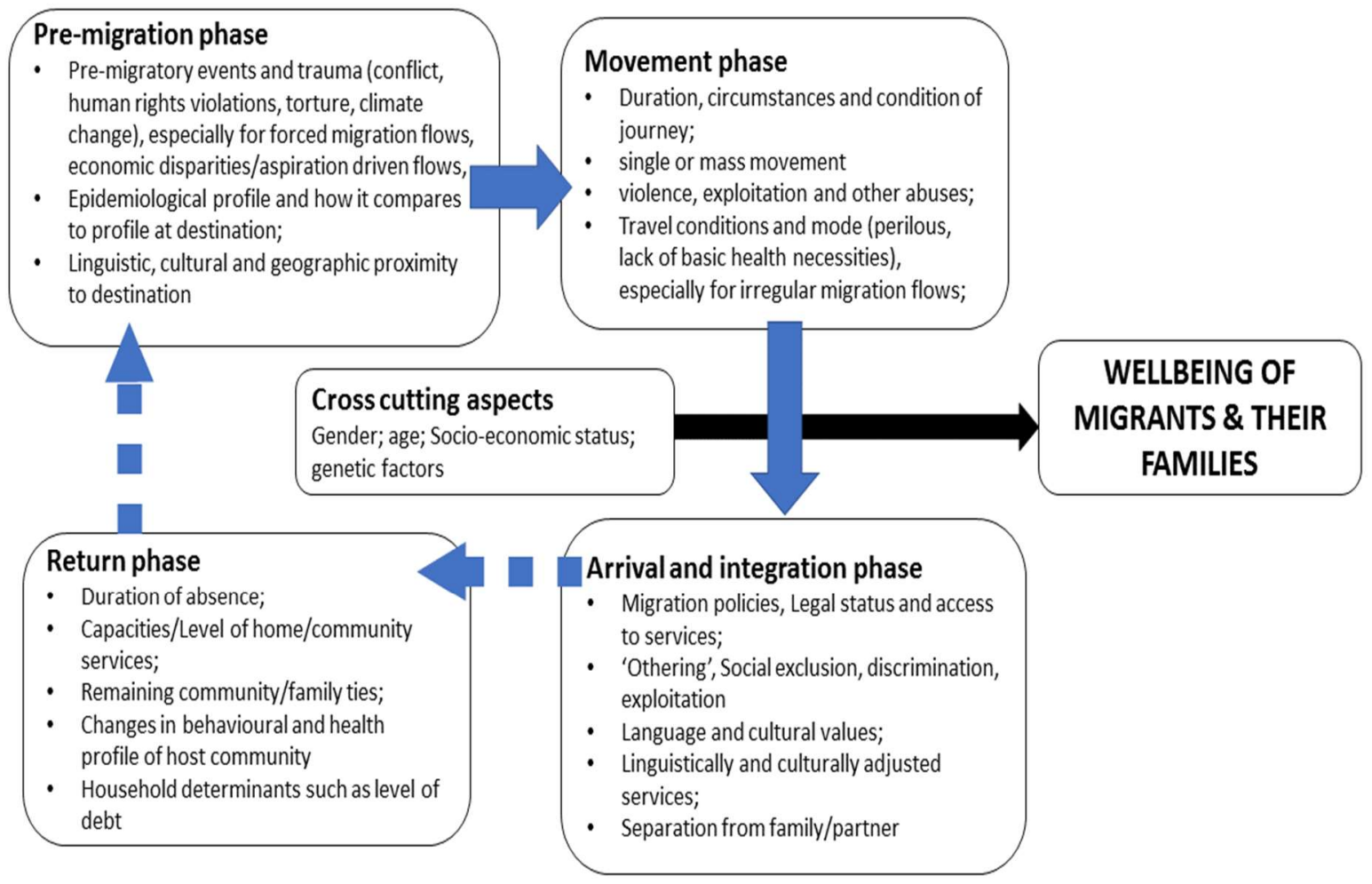

Source: https://migrationdataportal.org/themes/migration-and-health

If we analyse the variety of factors that impact the migrant health status, we need to relate them to the main phases of the migration process, namely pre-migration stage, the movement phase, the arrival and integration in the host country phase and the return phase. For forced migration, the need to escape conflict, persecution or natural disasters, as an act of despair or an attempt to survive may turn migrants in trauma carriers, who need support in order to avoid more abuses in transit or destination countries. Upon their arrival, in absence of adequate assistance, their health status is worsening (risks associated to improper/crowded housing, poor sanitary 
conditions, limited or poor quality food, sparse medical assistance etc.). For the economic migrants, the migration experience may have a significant impact on their physical and mental health (work related accidents, improper working conditions, various forms of work exploitation, etc.) and once they decide to return in home countries they may face failure in re-integrating in the home communities, another source for emotional distress. According to Hodges (2020), migrants are less likely to seek help, due to financial barriers, privacy concerns and social stigma. The mental health (in-depth analysis on the emotional and mental distress experienced by migrants have been carried out by Virupashka et al (2003) or Ujano-Batagan (2013), along with the physical one is seriously challenged in all the stages of the migration process, and the well-being of the migrants and their families depends both on the individual factors, as well as on the home and host countries conditions.

\section{Migrant workers and their vulnerabilities}

Usually, migrants are overrepresented in low skilled precarious jobs, as they are accessing the informal market, mainly the so-called $3 D$ jobs (dirty, difficult and dangerous), risking de-skilling, social stigma, low incomes, lack of access to social benefits or very limited, if any, access to healthcare services (except for emergency care). In Europe "the highest shares of migrant workers are among the cleaners and helpers (38\%), workers in mining and construction (23\%), stationary plant and machine operators (20\%) and personal care workers (19\%)" (Fasani \& Mazza,

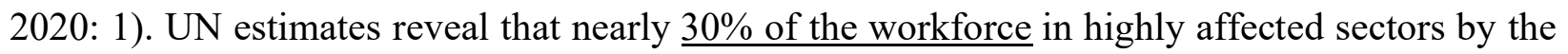
present pandemic in OECD countries is foreign-born (Testaverde, 2020).

Still, regardless their presence on the primary or secondary labour market, once they are employed, migrants contribute more to the social security system than they benefit from "migrants are vastly underserved by social protection systems around the world. They often pay taxes and contributions to these systems, but restrictive laws or administrative barriers limit their access to benefits. Over the long term, they are unlikely to constitute a disproportionate fiscal burden for destination countries" (UN, 2018:82).

In the same time, we should acknowledge that developed economies are in continuous search for skilled workforce, in the context of the alarming shrinkage of their native active population. If we refer to the present dramatic health crisis, we need to address the issue of essential/key-workers (those who perform jobs that are vital for the good functioning of the 
economy and society, in the pandemic context). According to Gelatt (2020) and Fasani and Mazza (2020), 19\% of key-workers in US and 13\% of key-workers in EU are migrants, and most likely they may preserve the privilege to have a job, in today's health crisis.

The usual vulnerabilities faced by most migrant workers refer to weaker status on the labour market, compared to native workers, prevalence of temporary contracts, fixed term contracts or informal jobs, less amenability to telework jobs, low level of incomes and therefore reduced capacity for savings, limited access to welfare benefits (especially for irregular migrants whose residence status negatively impacts their access to social benefits), limited access to healthcare, risks associated to the termination of the fixed term contracts, etc. A special attention should be paid to seasonal workers, who are undervalued and under protected due to weak statistical tools to count them properly. Thus, "the risks for seasonal workers are well documented and result from a combination of social and geographical isolation, precarious contracts and the harsh working conditions that come with the job"(Popp, 2020:3)

"The COVID-19 pandemic has revealed the reliance of many economies and public activities on migrant labour" (Popp, 2020:5). If we mention just those working informally in seasonal agricultural activities, we may realize the relevance of their contribution in today's crisis, despite the lack of protection provided by the host economies. During economic downturns, migrant workers are more likely to lose their jobs (Dustmann et al, 2010), to lose earnings, to reduce their ability to remit to their families back home, to exhaust their savings, to lose the chance to renew their residence documents and to be forced to return to or to become irregular migrants. This negative spiral may lead to their social exclusion, despite their efforts to preserve their fragile status in the host country. Therefore, we do believe that the host countries should pay attention to the socio-economic impact of the lockdowns and economic restrictions that are being imposed all over the world, on migrant workers and their families, who seem to lose the battle anyway due their vulnerabilities.

On one side, if we refer to essential workers, the pandemic associated health risks are considerable due to the fact that key migrant workers (working in health system, patient care system, hospitality sector - economic sectors that clearly require physical-proximity) are more exposed to contagion because they work in the frontline of COVID response activities. Probably, the advantage is represented by the limited risk to lose their jobs. Once infected, they still represent a risk for their families (they have reduced capacity to respect social distancing in small and 
crowded housing facilities), so access to proper healthcare is so needed for them and their dependents, as well as access to a financial safety net provided by the host country.

The others, non-essential migrant workers face also high contagion risks due to crowded housing facilities (according to Goddin (2020), several coronavirus outbreaks have impacted crowded refugee camps, where medical assistance is sparse). "COVID-19 has heightened the problem, as could be seen across Europe when a disregard for social distancing and hygiene measures in the housing and working conditions for seasonal migrant workers led to outbreaks and even the death of seasonal workers ( Popp, 2020:4), and due to the very nature of their jobs in informal market, that are also of physical proximity (elderly or children care, housekeeping, cleaning services, delivery, logistics, etc.).

Due to lockdowns and social distancing measures and subsequent fear of economic recessions, the whole interconnectivity that characterize the global world we live in has been dramatically affected. Moreover, many migrant workers couldn't afford the luxury to stay home, some became unemployed, dried up their savings and faced poverty risks. The families back home benefit less from remittances. Their dependents living in the host countries face poverty, exclusion, lack of access to social benefits or educational and professional training programmes. For the undocumented ones, as well as for seasonal workers, the access to healthcare is so limited, placing them in an unprotected environment, with potential risks to further spread the virus. Social stigmatisation of the poor and sick foreigner is not new (Bauomy, 2020), and nowadays we unfortunately witness aggressive attacks on social media, as well outrageous behaviours towards the most vulnerable persons, as in other turbulent times. "However, compared to previous diseases outbreaks, the issue of stigmatization seems to have received unprecedented attention given the scale of the pandemic, the clear guidance on its naming (from WHO), its media coverage and related commentary on political instrumentalization" (IOM, 2020:1). The spill over effects of the social stigmatization have been highlighted by WHO, influencing not just the migrants, but the host societies as well, because "stigma can: drive people to hide the illness to avoid discrimination, can prevent people from seeking healthcare immediately and might discourage them from adopting healthy behaviours". (IOM, 2020:2). 


\section{Some measures to be taken}

In order to limit the rapid spread of the infections the SDG principle "no one is left behind" needs to be addressed, meaning that availability of healthcare services for migrants, irrespective of their legal status in the host countries is both urgent and vital. The gaps in several national health systems place native, as well as migrant population in vulnerable positions. Thus, including the migrants in response policies all over the world will definitely support not only the vulnerable labour force, but the native populations, as well.

Protecting the health and economic status of the migrants reduces the risks of transmission for the entire population and allows the host countries to preserve the so needed labour force, in essential activities, during pandemic times, and during economic downturns expected to impact us globally.

The main active measures proposed by the World Bank refer to the following (Testaverde, 2020:4):

- $\quad$ Extend or create social safety nets - they provide direct support either in the form of cash or in-kind goods and services to support consumption, compensate for expected higher prices, and prevent poverty associated risks. The existing safety net programs should be extended and migrants should become beneficiaries, with a special attention given to their needs (health related, economic related, or both). If such programs are not available, the present pandemic clearly asks for government to launch solidarity and support programs for the vulnerable members of the society;

- $\quad$ Promote employment retention policies - focused on motivating the employers to preserve the jobs of those at high risks to lose any income (deductions in social insurance contributions, tax exemptions)

- Design employment promotion policies focused on labour market mediation services that might help employers to find workers and jobseekers to access jobs.

Along with initiatives promoted by WHO, UN or IOM, our attention was caught by some clear statements on the migrants' health and protection that have been launched by Lancet 
Migration, an initiative of migrationandhealth.org. ${ }^{2}$ They ask for urgent measures to be taken in order to avoid huge labour market imbalances and post-pandemic economic turmoil:

- Urgent access to healthcare for all migrants \& refugees throughout the response to Covid$\underline{19}$ - basically, it refers to immediate suspension of laws that limit migrants and refugees access to healthcare services and economic support programs;

- Inclusion of all migrant and refugee populations in prevention, preparedness for and response to Covid-19 - it refers to awareness and educational campaigns, and support service;

- Urgent relocation and reunification of unaccompanied minors, who are particularly vulnerable - the last massive migration inflows a relevant part is represented by unaccompanied children, exposed to serious emotional and physical distress (Cramarenco, 2018:107);

- Fast-tracking temporary accreditation of overseas degrees can help overcome the human resources deficit registered in most healthcare systems - this initiative will probably re-activate the whole process of diplomas and professional qualifications' recognition;

- Clear, transparent public communication is critical in pandemic response, including those facing linguistic barriers - access to relevant information campaigns;

- Governments should also actively counter racism, xenophobia and discrimination against migrants and refugees, through awareness campaigns - the rise of social stigmatization may be counterattacked by balanced, informed official discourse.

\section{Concluding remarks}

The on-going COVID-19 pandemic exacerbates, once again, some of the vulnerabilities faced buy migrants and refugees worldwide. We need to acknowledge that they do not represent just a financial burden for the host countries or a threat to the health of the native populations. Both migrant key workers as well as those performing jobs in non-essential sectors of economy, along with refugees and asylum seekers that depend on the safety nets created by the host countries, should have access to healthcare services and financial support, to avoid facing disease and extreme poverty associated risks.

\footnotetext{
${ }^{2}$ Several resources might be find here: https://www.migrationandhealth.org/migration-covid19
} 
The lockdowns and mobility restrictions seriously limit the migrants' ability to maintain jobs, to find other jobs when they are laid off, to access social benefits or appropriate housing facilities.

Our preliminary findings highlight the potential benefits of an inclusive approach in COVID-19 policy response, mitigating the "no one is left behind" principle. The healthcare systems are under enormous pressure, a relevant portion of essential workers are migrant workers, so in order to protect both native populations and newcomers, decision-makers, entrepreneurs, NGOs and migrants' associations need to co-design efficient interventions, to control the pandemic and to identify appropriate support mechanisms for the economic sectors facing downturns.

\section{References}

1. ARLOTH, J. (2010) - Book review on Andrew Clapham, Mary Robinson (eds) and Claire Mahon, Scott Jerbi (co-eds.): Realizing the Right to Health. Available at: https://link.springer.com/article/10.1007/s10389-009-0293-2. [Accessed on 10.09.2020].

2. BAOUMI, J. (2020), COVID-19 and xenophobia: Why outbreaks are often accompanied by racism. Available at: https:/www.euronews.com/2020/03/05/covid-19-andxenophobia-why-outbreaks-are-often-accompanied-by-racism, [Accessed on 10.09.2020].

3. DAVIES et al (2006), Migration: a social determinant of migrants' health. Available at: http://citeseerx.ist.psu.edu/viewdoc/download?doi=10.1.1.462.6286\&rep=rep1\&type=pdf, [Accessed on 10.08.2020].

4. DUSTMANN et al (2010) - Assessing the Fiscal Costs and Benefits of A8 Migration to the UK. Available here:

https://www.ucl.ac.uk/ uctpb21/Cpapers/DustmannFrattiniHalls2010.pdf [Accessed on 13.09.2020].

5. FASANI, F. \&MAZZA, J. (2020), Immigrant Key Workers: Their Contribution to Europe's COVID-19 Response. Available at:

https://ec.europa.eu/knowledge4policy/sites/know4pol/files/key_workers_covid_0423.pd f. [Accessed on 13.09.2020].

6. GELLAT, J. (2020), Immigrant Workers: Vital to the U.S. COVID-19 Response, Disproportionately Vulnerable. 
Available at: https://www.migrationpolicy.org/research/immigrant-workers-us-covid-19response. [Accessed on 13.09.2020].

7. GODDIN, M. (2020) - COVID-19 Outbreaks Are Now Emerging in Refugee Camps. Why Did it Take so Long For the Virus to Reach Them? Available at: https://time.com/5893135/covid-19-refugee-camps/. [Accessed on 13.09.2020].

8. HODGES, L. (2020) - Going to Therapy Can Be Hard, especially for Immigrants - Here's How to Start. Available at: https://www.npr.org/2020/01/23/799004218/going-totherapy-can-be-hard-especially-for-immigrants-heres-how-to-start?t=1603984575171 [Accessed on 13.09.2020].

9. WILKINSON, R. \&MARMOT, C. (2003) - Social determinants of health. The solid facts, $2^{\text {nd }}$ edition, WHO. Available at: https://www.euro.who.int/_data/assets/pdf_file/0005/98438/e81384.pdf?u, [Accessed on 10.08.2020].

10. MC MICHAEL, C. (2020), Human mobility, climate change, and health: unpacking the connections. Available at: https://www.thelancet.com/journals/lanplh/article/PIIS2542-5196(20)30125-X/fulltext [Accessed on 13.09.2020].

11. PETROZZIELlO, A, (2003) - Gender on the Move: Working on the MigrationDevelopment Nexus from a Gender Perspective. Available at: https://trainingcentre.unwomen.org/instraw-library/2012-T-MIG-GLO-EN.pdf, [Accessed on 12.09.2020].

12. POPP, K. (2020), Seasonal migration and COVID-19: undercounted, undervalued and under protected. Available at: https://migrationdataportal.org/blog/seasonal-migration-andcovid-19-undercounted-undervalued-and-underprotected) [Accessed on 23.09.2020].

13. SEMENZA et al (2016) - Public health needs of migrants, refugees and asylum seekers in Europe, 2015: Infectious disease aspect,_European Journal of Public Health, Volume 26, Issue 3, June 2016, Pages 372-373, https://doi.org/10.1093/eurpub/ckw023. Available at: https://academic.oup.com/eurpub/article/26/3/372/2467352 [Accessed on 13.09.2020].

14. TESTAVERDE, M. (2020), Social protection for migrants during the COVID-19 crisis: The right and smart choice. Available at: https://blogs.worldbank.org/voices/socialprotection-migrants-during-covid-19-crisis-right-and-smart-choice. [Accessed on 23.09.2020]. 
15. UJANO-BATAGAN, T. (2013) - Women and Migration: Women and Migration: Women and Migration: THE MENTAL HEALTH NEXUS A Research on Individual and Structural Determinants of Stress and Mental Health Problems of Filipino Women Migrant Domestic Workers. Available at: https://www.jnsbm.org/temp/JNatScBiolMed52233-5048129_140121.pdf, [Accessed on 12.09.2020].

16. VIRUPASKA et al. (2003) - Migration and mental health: An interface. Available at:

http://www.migration4development.org/sites/default/files/women_and_migration_the_mental_he alth_nexus.pdf, [Accessed on 10.08.2020].

17. *** IOM (2020), IOM, 2020- COVID-19 Analytical Snapshot \#6: Stigmatization \& discrimination. Available at: https:/www.iom.int/sites/default/files/documents/covid19_analytical_snapshot_6_-_stigmatization_and_discrimination.pdf, [Accessed on 20.10.2020].

18. *** OECD (2020) - Territorial impact of COVID. Available at: https://www.oecd.org/coronavirus/policy-responses/the-territorial-impact-of-covid-19-managingthe-crisis-across-levels-of-government-d3e314e1. Accessed on 20.10.2020].

19. *** United Nations (2018), The Report on the World Social Situation 2018. Promoting Inclusion Through Social Protection. Ch 3 International Migrants: Carrying their own weight. Available at: https://www.un.org/development/desa/dspd/wpcontent/uploads/sites/22/2018/07/Chapter-VIInternational-migrants-carrying-their-own.pdf, [Accessed on 10.08.2020].

Relevant websites:

www.migrationdataportal.org

www.migrationpolicy.org

www.iom.org

www.who.org 